AperTO - Archivio Istituzionale Open Access dell'Università di Torino

\title{
Ambidextrous IT capabilities and business process performance: an empirical analysis
}

\section{This is the author's manuscript}

Original Citation:

Availability:

This version is available http://hdl.handle.net/2318/1663212

since 2020-07-03T15:10:08Z

Published version:

DOI:10.1108/BPMJ-07-2017-0201

Terms of use:

Open Access

Anyone can freely access the full text of works made available as "Open Access". Works made available under a Creative Commons license can be used according to the terms and conditions of said license. Use of all other works requires consent of the right holder (author or publisher) if not exempted from copyright protection by the applicable law.

(Article begins on next page) 


\title{
Ambidextrous IT capabilities and business process performance: an empirical analysis
}

\author{
Alberto Ferraris \\ Department of Management, University of Turin, Turin, Italy and \\ Laboratory for International and Regional Economics, \\ Graduate School of Economics and Management, \\ Ural Federal University, Yekaterinburg, Russia \\ Filippo Monge \\ University of Turin, Turin, Italy, and \\ Jens Mueller \\ University of Waikato Waikato Management School, Hamilton, New Zealand
}

Corresponding author Alberto Ferraris can be contacted at: alberto.ferraris@unito.it

\begin{abstract}
Purpose In several studies, it has been found that organizational performance is affected by ambidextrous IT capabilities. Nevertheless, business processes are essential to the value generation conversion of IT investment into performance. In the literature, this focus on the impact of IT capabilities at the business process level is still under investigated. So, the purpose of this paper is to test the effects of explorative and exploitative business process IT capabilities on business process performances (BPP) and the positive moderator role of business process management (BPM) capabilities.

Design/methodology/approach This analysis has been done through a quantitative study in the Italian hotel industry. An OLS regression analysis has been carried out on a sample of 404 firms.

Findings The study identifies distinct effects related to exploration and exploitation and finds a moderating effect of BPM capabilities, explaining their positive impact on BPP.

Originality/value The main purpose of the paper is to contribute to the area of business process management by demonstrating the importance of both explorative and exploitative IT capabilities for a business process as well as the managerial capabilities at the process level. Furthermore, this focus at the process level allows us to add original insights into research on ambidexterity by expanding existing works.

Keywords Business process management, Ambidextrous BPM, Business process IT capabilities,

Explorative BPM, Exploitative BPM, Business process management capabilities

Paper type Research paper
\end{abstract}

\section{Introduction}

Since the 1970s, organization theorists (e.g. Duncan, 1976) have been attracted by the notion of organizational ambidexterity. Indeed, a very long time ago Abernathy (1978) suggested that a firm's ability to compete over time was rooted not only in its ability to increase its efficiency but also in its ability to be efficient and innovative at the same time. Afterwards, a consistent series of research across different disciplines in organizational adaptation appeared (e.g. March, 1991). The need for dual organizational capabilities has been raised amid a period of florid managerial activity and institutional pressures involving business process management (BPM) and control (e.g. Adler, 1993; Hackman and Wageman, 1995; Hammer and Stanton, 1999). In this regard, Davenport (1993) defines the business process as "the specific ordering of work activities across time and space with a beginning, an end and clearly identified inputs and outputs."

Much of the existing literature is prescriptive and aims at enlightening managers on implementing process management practices (Benner and Tushman, 2003). Scholars have promoted new practices related to processes that result in efficiency improvements, cost 
decreases, improved customer satisfaction and eventually, higher profits (Hammer and Stanton, 1999; Vrontis et al., 2017).

Nowadays, in times of ever-increasing competition and an extremely dynamic economic environment, the achievement of both efficiency and flexibility to maintain competitiveness is needed even more (Bresciani et al., 2017; Ferraris et al., 2017), as much as the need to achieve better performance at the business process level (Zairi, 1997; Karimi et al., 2007). In this context, information technology (IT) capability, i.e. the provisioning of IT to sustain business processes (BP), has become increasingly vital and is acknowledged to contribute to both efficiency and flexibility (Del Giudice and Straub, 2011; Chen et al., 2014). However, firms usually have financial constraints on IT budgets and need to decide how to allocate money on efficiency-enhancing and flexibility-enhancing IT capabilities to support the execution of BP in the best possible way (Heckmann, 2015).

$\mathrm{BP}$ are central to the conversion of IT investments into performance, but in the literature the impact of IT capabilities at the business process level is still under investigated. In this paper, we test the effect of explorative and exploitative business process IT (BPIT) capabilities on business process performances (BPP) and the positive moderator role of BPM capabilities. Thus, we aim at bringing greater conceptual clarity to the management of ambidexterity at the business process level and empirically validating it. So, based on a sample of 404 firms in the Italian hotel industry, we have examined and found empirical evidence of positive effects of explorative and exploitative IT capabilities on BPP and of the positive moderator effects of BPM capabilities.

The paper is organized as follows. Section 2 reviews the literature on ambidextrous IT capabilities, with a particular focus on the business process level. Section 3 proposes four hypotheses relating to the direct effects of explorative and exploitative IT capabilities on $\mathrm{BPP}$ and of the moderator effects of BPM capabilities. Section 4 explains the research design of this study, and Section 5 presents the OLS regression test of the hypotheses and the related results. The last section presents a concluding discussion, identifying managerial implications and issues for future research.

\section{Literature backbone}

\subsection{Ambidextrous IT capabilities}

Wade and Hulland (2004) recognized IT capabilities as a key organizational competence that is able to mobilize and deploy IT-based resources in combination with other organizational resources and capabilities. Bharadwaj (2000) indicates that firms that possess superior IT capabilities tend to achieve better performance than competitors on different profit- and cost-based performance measures. In this regard, some researchers (e.g. Rai and Tang, 2010) put their focus on the competitive advantage linked to specific IT capabilities such as IT management. However, this could actually be too narrow a focus to reveal the aim of the business value of IT (Bharadwaj, 2000; Lu and Ramamurthy, 2011) since specific IT capabilities tend to generate advantages in the short-term period and it underestimates the interconnection and interrelation among different specific IT capabilities.

Drawing on the literature on ambidextrous organizational IT capability (Lee et al., 2008), two distinct types of activities have been identified: exploitation and exploration. The conventional assumption is that exploitative and explorative IT capabilities require different skills and competencies (Ferraris et al., 2018). Explorative activities require abilities that include a broad and creative understanding of the business and the market as well as an overview of modern technological innovations to the objective of achieving flexibility. On the other hand, the know-how that is required for exploitative activities includes a deeper and more technical awareness of implemented systems and business process specifics, with the objective of achieving efficiency using already-deployed resources (Wade and Hulland, 2004; Lu and Ramamurthy, 2011). 
Some research has aimed at evaluating backgrounds for ambidextrous IT capability, showing the importance of the alignment between BP and IT as well as the effect of IT as an enabler of modular BP (Ling et al., 2009). In fact, Benner and Tushman (2003) clearly argued that, at the business process level, ambidexterity is related to the pursuit of two different categories of BPM practice: explorative variation-decreasing; exploitative efficiency-oriented.

\subsection{Business process IT capabilities and performances}

The role of technology in BPM underlines how IT is likely to have a positive impact on individual performance and should be used if the IT capabilities match the tasks that the user must perform (Goodhue and Thompson, 1995). IT will be used if the functions accessible to the user support (fit) the kinds of activities (Dishaw and Strong, 1999). Many of the studies on this topic have focused on the organizational level, highlighting how IT positively affects performances if it matches the BP (Karim et al., 2007). In this way, Smith and Fingar (2003) stated: "IT does not matter, business processes do." The corporate IT function must be strongly coupled to enterprise processes and the organization's information needs (Strnadl, 2006). A well-known claim is that IT is becoming a commodity which is not able to bring a sustainable competitive advantage (Carr, 2003). Even though companies have made significant investments in IT, a considerable number of these have not been able to derive full benefits due to their inability to use IT resources (Karim et al., 2007; Trkman, 2010).

In general, $\mathrm{BP}$ have proved crucial to the value-generation process for converting IT investments into performance (Melville et al., 2004; Attaran, 2004). From the moment that IT budgets are limited, many companies face a dilemma over how much to invest in exploitative capabilities, i.e. leveraging existing IT capabilities to support BP, and/or in explorative capabilities, which focus on achieving access to new and innovative IT capabilities to support BP. In such cases, trade-off thinking is prevalent (Chen et al., 2014). However, management research has observed a shift from such trade-off thinking towards paradoxical thinking (Gibson and Birkinshaw, 2004), which argues for striving simultaneously for short-term efficiency through exploitation of existing resources and for long-term flexibility through exploration of new resources (He and Wong, 2004).

Business process ambidexterity is considered as dynamic equilibrium of business process efficiency and flexibility, and its main purpose is to have an impact on BPP (Xie et al., 2011). Thus, the ambidexterity concept is adapted to the BPIT context (Gebauer and Schober, 2006; Lee et al., 2008; Joachim et al., 2013).

\section{Hypothesis development}

Organizations are usually considered as a set of interlinked BP which meaningfully influence organizational strategy and performance (Benner and Tushman, 2003). BP are the vehicle through which business value is created from technological IT resources (Melville et al., 2004) such as functional systems, enterprise systems or BPM platforms. In times of highly dynamic business environments, IT flexibility is important to rapidly adapt BP to fluctuating customer demands and implement innovative technologies (Lu and Ramamurthy, 2011; Chen et al., 2014; Kumar and Stylianou, 2014). Based on Heckmann (2015), this activity is defined as explorative BPIT capabilities with the aim of identifying and implementing the usage of innovative and new IT resources to support a business process in order to achieve better performance. Firms can do this by integrating new IT resources into the IT infrastructure already in action (Joachim et al., 2013). Some mechanisms should be developed in order to allow the mixing and matching of task implementations to adapt quickly to changing requirements (Schilling, 2000), for example complementing the core ERP system with individual spreadsheet solutions (Alter, 2014). Higher levels of explorative BPIT capabilities indicate a focus on identifying and adopting new and innovative IT resources that have the potential to support BP in the future. 
Explorative BPIT capabilities can be seen as digital options, which are particularly crucial in dynamic environments (Sambamurthy et al., 2003). In order to adopt new IT resources continuously and to integrate them with the company's IT infrastructure, a modular architecture is required (Ling et al., 2009). This can be implemented by using service-oriented architectures (Joachim et al., 2013) or platform approaches (Tiwana et al., 2010). The constant ability to integrate the latest value-adding IT components provides the potential to innovate BP regularly (Gebauer and Schober, 2006). Thus, we propose the following:

H1. The greater the explorative BPIT capabilities of the firm, the higher is the BPP.

In contrast, the concept of exploitation is associated with structures and systems that are more mechanical, routinized and with much more control (Gibson and Birkinshaw, 2004; He and Wong, 2004). The focus here is to get the highest yield out of the current IT resources to support processes. A possible way of making this possible is automation (Shang and Seddon, 2002), which can be increased by implementing tasks that so far have been manually performed using IT. Furthermore, tight connections between IT resources are created through various integration mechanisms, which allow automation not only for specific tasks but also for complete BP (Bahli and Ji, 2007).

High levels of exploitative BPIT capabilities, i.e. investing heavily in task automation and data integration capacities, indicate that BP are widely supported by IT with a focus on process automation. This allows companies to implement high-performance BP (Bahli and Ji, 2007). Efficiency-oriented exploitative BPIT capabilities are suggested as a requirement to capitalize on BP with high levels of explorative capabilities in place (Tang and Rai, 2014). Thus, we propose the following:

H2. The greater the exploitative IT capabilities of the firm, the higher is the BPP.

In spite of these benefits, companies emphasizing explorative and exploitative BPIT capabilities often fail to operate their BP economically. As they frequently exploit and adapt their BP, there is time for neither process harmonization nor optimization (Joachim et al., 2013; Muenstermann et al., 2009). If the investments in the development of capabilities are not adequate, the firm is not able to limit the risk of becoming too inflexible in case of environmental change (Gebauer and Schober, 2006; Kumar and Stylianou, 2014). As process management techniques focus on continuous improvement in routines and variation reduction (Hackman and Wageman, 1995), their increased use in an organization affects the balance between exploratory and exploitative innovation (Benner and Tushman, 2003). In this regard, firms may develop business process management (BPM) capabilities that represent the capacity to manage some activities continuously in order to guarantee the delivery of high quality standards of products and services (Zairi, 1997). BPM capabilities are defined as the ability to coordinate different skills and integrate multiple streams of technology with other resources and capabilities (Wong et al., 2014). Rosemann and Brocke (2010) categorized BPM capabilities in the following way: strategy management, program and project management, complexity management and vendor management. On the other hand, according to Hung (2006), BPM capabilities can be divided into two elements: management commitment and employee empowerment, focusing more on human resources and people involvement. These features are important in the business process maturity model (Looy et al., 2011) to ease the journey towards achieving business excellence.

In general, the development of BPM capabilities allows the management of critical and all-encompassing activities of design, manufacture, marketing, innovation, sales and others which bring quality to the final customers and that can be the focus of IT investments (both explorative and exploitative).

Our analysis draws upon an extensive body of research in management and organization science that has focused on the management of trade-offs of ambidextrous objectives 
(Gibson and Birkinshaw, 2004; He and Wong, 2004). The managerial capabilities formed by organizational characteristics and human resources, as well as IT and business process characteristics play a crucial role for realizing benefits from IT (Melville et al., 2004). Ravichandran and Lertwongsatien (2005) argued that the variation in performance may be explained by the extent to which IT capability is used to support and enhance core competencies and capabilities. Thus, BPM capabilities may cover a relevant role in improving the impact of both explorative and exploitative IT investments on BPP (Melville et al, 2004; Shang and Seddon, 2002). Thus, we propose the following (Figure 1):

H3. The impact of explorative IT capabilities on BPP will be stronger for firms with higher levels of BPM capabilities (moderation effect).

H4. The impact of exploitative IT capabilities on BPP will be stronger for firms with higher levels of BPM capabilities (moderation effect).

\section{Data and methodology}

\subsection{The context of analysis}

We have selected the hotel industry sector because this sector provides highly dynamic and competitive environments. Among the main reasons are the recent alterations in the industry due to the increasingly important and emerging role of new business models such as AirBnB that leads to changing customer demand, bringing higher levels of process uncertainty. These require hotels to be highly flexible and to adapt their business models and processes continuously (Krstić et al., 2012).

A distinctive feature of hotel management theory concerns the complexity arising from the range of diverse activities undertaken (Thrassou et al., 2014). The hotel manager too often has to cover many roles within the firm, and often key core competencies required are not developed enough, resulting in lower performance (Hemmington and King, 2000). Some researchers such as Chenhall (2006) note an overall increase in the importance of service industries and in detail cite the hospitality and tourism sectors as providing opportunities for upcoming studies.

Three main important challenges affect the industry today: globalized business environment, technology development and changing customer demand. The first one is related to the increasingly competitive environment of the hotel and lodging enterprises in all geographic regions. The second challenge is the tremendous increase in the sophistication of IT and social network of hotels (e.g. AirBnB, as mentioned before) while

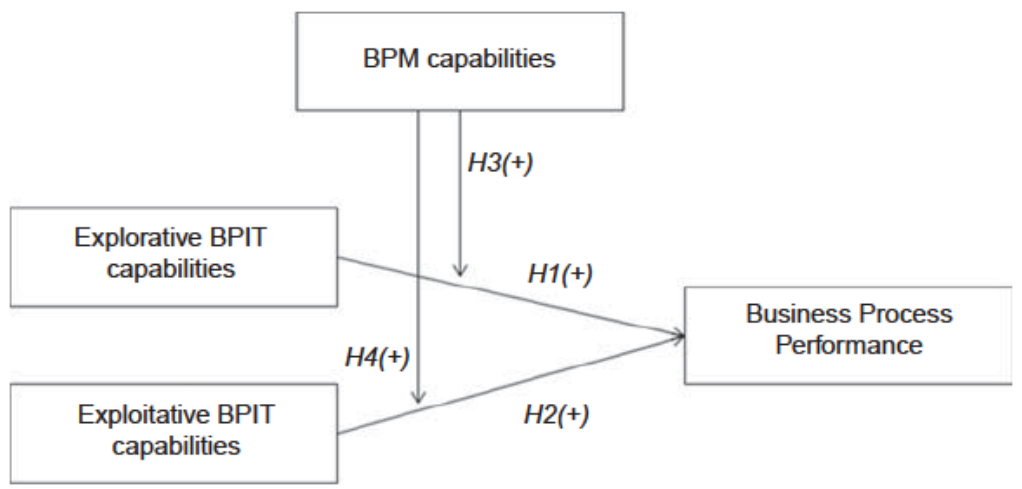

Source: Own elaboration

Figure 1. The hypothesized relationships 
the third challenge is the increasingly demanding requests of hotel guests. Thus, firms that operate in this industry are forced to innovate their business models faster and must focus on customers, competition and processes. These new business models have been described as "business process management system", which means that a focus is placed on the business process (Krstić et al., 2012). All these facts forced us to choose this industry as the context of analysis for this study.

\subsection{Analysis}

For this study, a survey on exploitative and explorative BPIT capabilities and the corresponding BPP has been conducted with firms in the hotel industry in Italy at the beginning of 2015. Therefore, using a standardized questionnaire, the postal survey collected specific data. Regarding our kind of analysis, a major difficulty was to detect relevant survey participants, which in this case consisted of business process owners and/or line-of-business managers, who are responsible for BP. In contrast to CEOs, there is no publically accessible listing of such persons, nor is it easy to identify these using company databases, company websites or social media (Heckmann, 2015). Thus, we collaborated with a well-established Italian trade association which provided us with a pool of 600 relevant study participants, including only those which have a minimum of 65 bedrooms, which are demonstrative of the region and which have a star rating of 3 or more (on a rising scale of 1-5). The literature had already adopted these criteria in the past (Hoque, 1999; Thrassou et al., 2014). As the study is conducted in Italy, the questionnaire has been developed in the Italian language, making a forward-backward translation of the items that are adapted from the English literature necessary (Cha et al., 2007).

Data collection took place as follows. First, the purpose of the research was explained in a cover letter and their participation was requested. Then, we made reminder phone calls to encourage participation. After this procedure, the ultimate sample consisted of 404 firms in the hotel industry (response rate was $404 / 600=67$ percent) from which we received completed and usable questionnaires. Following the studies of Kanuk and Berenson (1975), we assessed potential non-response bias by looking for differences between early and late respondents. To do so, the order of responses to the survey was recorded and it was revealed to be non-significantly correlated with both firm age $(r=0222, p=0154)$ and firm size ( $r=0$ 027, $p=0$ 633), suggesting that concern regarding non-response bias is minimal (Hawes and Crittenden, 1984). We also found no substantial differences in either firm age $(F=1128, p=0344)$ or firm size $(F=1523, p=0126)$ across industries. The 404 firms in the final sample average 97 employees in size, 1.1 million euro in sales, and eight years in age.

Regarding the questionnaire, many precautions were taken in order to limit potential common-method variance by placing dependent and independent variables or items for constructs at diverse positions in the survey (Yamin and Andersson, 2011). We also placed the dependent variables after the independent variables in the questionnaire in order to decrease the effects of consistency artefacts (Salancik and Pfeffer, 1977). From the flow of the questionnaire, it was unlikely that respondents could guess hypothesized relationships between constructs, thereby avoiding social desirability prejudice. Moreover, the questions and indicators used in the present research were commonly divided in the questionnaire, reducing the risk of respondents' rationalizing their answers (Ciabuschi et al., 2011), and the use of two different endpoints (1-7 and -3-3) also established methodological separation of measurement (Podsakoff et al., 2003).

It should be accepted that studies using self-reports are particularly susceptible to mistakes resulting from consistency bias and problems associated with common-method prejudice (Podsakoff and Organ, 1986). So, although the questionnaire was designed in such a way that the variables were spread across the questionnaire to avoid socially desirable 
replies, a "Harman's one-factor test" on the items included in our model was conducted (Harman, 1967). In performing this test, several factors were discovered (four factors with an eigenvalue greater than 1), and the factors accounted for 20,14, 12 and 11 percent of the variance, respectively, which indicates that our research does not appear to be affected by common-method bias.

\subsection{Variables employed in the study}

BPP generally includes three dimensions: cost, time and quality (Karimi et al., 2007). Cost reflects the efficiency-oriented perspective (Gebauer and Schober, 2006). The value of being capable of responding to changing conditions fast and flexibly is addressed through time. Quality covers customer-orientation and the possibility of differentiating firm's value proposition through particular BP (Ray et al., 2005). Performance can be seen as an absolute or a relative measure. Relative measures are used to relate performance before and after an intervention, e.g. implementation of an ERP (Karimi et al., 2007) or to compare performance between firms. Furthermore, BPP cannot be measured precisely without acknowledging the specifics of a business process (Ray et al., 2004). Consequently, most existing measurement scales for BPP address specific BP, such as customer service (Ray et al., 2005), sales (Reinartz et al., 2004) or recruitment (Muenstermann et al., 2010). These measurement scales are typically self-reported measures, and they are found to be positively correlated with objective performance measures, such as customer satisfaction measured through a customer survey and objective measures such as the retention rate (Ray et al., 2004). For this study, the customer service business process has been analyzed by using the following seven items (Ray et al., 2005) on a 1-7 Likert scale (from -3 to +3 ): CSP1 - "The customer service unit gives customers prompt service"; CSP2 - "Customer service representatives are never too busy to reply to customers"; CSP3 - "Customer service representatives are empowered to elucidate customers" problems; CSP4 - "When the customer service unit promises to do something for a client by a certain time, it does so"; CSP5 - "When a customer has an issue, the customer service unit shows sincere interest in solving it"; CSP6 - "The customer service unit performs the service accurately the first time"; and CSP7 - "Customer service representatives understand customers". The Cronbach $\alpha$ for this measure is 0.79 .

For the measurement of BPM capabilities, based on the studies of Zairi (1997), a seven-point Likert scale (from 1 to 7 ) was developed, asking the respondents to evaluate the following matters: "Major activities have to be properly mapped and documented"; "Our firm creates a focus on clients through horizontal linkages among key activities"; "Our firm adopts systems and procedures to ensure repeatability, consistency and discipline of quality performance"; "Our firm carefully measure activities to assess the performance of each individual procedure, set targets and deliver output levels which can meet corporate objectives"; "Our firm has to be based on a continuous approach of optimization through problem solving and reaping extra benefits"; "Our firm has to be inspired by best practice to ensure that superior competitiveness is achieved"; and "Our firm has an approach for culture transformation and does not result simply through having worthy systems and the right structure in place." The Cronbach $\alpha$ for this measure is 0.84 .

For the measurement of IT ambidexterity through the dimensions of explorative and exploitative BPIT capabilities, we adapted He and Wong's (2004) scale for organizational ambidexterity, which consists of items addressing exploration and exploitation, to the context of this research following established procedures. To collect data for these measures, business process owners/line-of-business managers were asked to indicate, on a 1-7 Likert scale, the extent to which eight diverse statements were accurate regarding product development in their firm over the past three years. Four of the statements related to the firm's exploration (i.e. new and innovative IT resources to support the introduction of new generations of products, extension of product range, opening up new markets and 
entering new technological fields), and this allowed us to construct the variable explorative BPIT capabilities. Four pertained to exploitation (i.e. leveraging existing IT resources to support the improvement of existing products, improvement of product flexibility, reduction of production cost and enhancement of existing markets), and this allowed us to build the variable exploitative BPIT capabilities. The Cronbach $\alpha$ for the exploration measure is 0.84 and 0.83 for exploitation. Composite reliability for BPP (0.88), exploration (0.81) and exploitation (0.79) combined with Cronbach $\alpha$ confirm a good level of reliability (Fornell and Larcker, 1981).

Lastly, several control variables in the overall model were also used because they may impact on BPP: firm size (as measured using the number of employees), firm age (as measured using the number of years from the date of birth) and three geographical dummy variables in order to catch differences among the North, Center and South of Italy.

\section{Results}

We tested the hypotheses using OLS regression analysis, and we present the results in Table I. Model 1 represents the effect of the control variables only on BPP. Model 2, on the other hand, is implemented to test the impact of the two independent variables (explorative and exploitative BPIT capabilities). Finally, in Model 3 the interaction terms are proposed to test the moderator effect of BPM capabilities. Model 1 has an $R^{2}$ of 0.17 (adjusted $R^{2}$ is 0.12 ) and an $F$-value of $3.01(p<0.05)$. Model 2 has an $R^{2}$ of 0.56 (adjusted $R^{2}$ is 0.48 ) and an F-value of $4.67(p<0.001)$. Model 3 has an $\mathrm{R}^{2}$ of 0.66 (adjusted $R^{2}$ is 0.59$)$ and an $F$-value of $7.22(p<0.001)$.

The outcomes of the empirical analysis indicate that explorative and exploitative BPIT capabilities positively affect the BPP of firms of the hotel industry in our example. Both coefficients are positive and significant, so $\mathrm{H1}$ and 2 are confirmed. The analysis proves that exploitative BPIT capabilities have a greater impact than the explorative BPIT one on BPP; in fact, in Model 2, exploitative BPIT capabilities showed a standardized coefficient of 0.33 with $t$-value of 3.64 (significant at the 1 percent level) compared to 0.22 with $t$-value of 2.16 (significant at the 5 percent level) of the second one.

The most remarkable and innovative result of this study emerges when the interaction terms enter in the regression model. Along with the procedures for testing interaction effects suggested by Aiken and West (1991), the independent variables were standardized before creating the multiplicative terms, thus reducing possible distortion caused by strong correlations between the interaction term and its components. Model 3 presents the consequences of the moderation effects of BPM capabilities. The results indicate that $H 3$ and 4 are supported because the interaction term is positive and significant. In other words, firms that possess strong BPM capabilities amplify the positive effects of both explorative

\begin{tabular}{llcc}
\hline & \multicolumn{3}{c}{ Business process performance (BPP) } \\
Variables & Model 1 & Model 2 & Model 3 \\
\hline Explorative BPIT capabilities & & $0.22(2.16)^{*}$ & $0.14(1.68)^{*}$ \\
Exploitative BPIT capabilities & & $0.33(3.64)^{* *}$ & $0.27(3.12)^{* *}$ \\
Explorative BPIT capabilities x BPM capabilities & & & $0.24(3.07)^{* *}$ \\
Exploitative BPIT capabilities x BPM capabilities & & & $0.39(3.23)^{* *}$ \\
Firm size & $0.09(2.22)^{*}$ & $0.02(2.17)^{*}$ & $0.14(2.41)^{*}$ \\
Firm age & $0.06(0.43)$ & $0.02(0.46)$ & $0.08(0.61)$ \\
Geography 1 $(1=$ North of Italy, $0=$ no) & $0.03(0.29)$ & $0.05(0.23)$ & $0.08(0.18)$ \\
Geography 2 $(1=$ Center of Italy, $0=$ no) & $0.06(0.22)$ & $0.03(0.20)$ & $0.03(0.15)$ \\
Geography $3(1=$ South of Italy, $0=$ no) & $0.07(0.75)$ & $0.04(0.41)$ & $0.05(0.44)$ \\
Notes: $* p<0.05 ; * * p<0.01$ & & & \\
\hline
\end{tabular}

Table I. Results of the regression analysis 
and exploitative BPIT capabilities on BPP. Concerning the control variables, one of the variables employed in the different regressions significantly explains a part of the variance in the BPP (see Model 1 in Table I). Surprisingly, there are no significant differences in the geographical location of the hotels.

\section{Discussion}

\subsection{Main implications}

The main goal of this paper was to investigate the impact of diverse strategies for exploitative and explorative BPIT capabilities on BPP and to test the potential moderator effect of BPM capabilities on these relationships. Outcomes based on the answers of 404 process owners/line-of-business managers in the Italian hotel industry confirmed our four hypotheses highlighting the positive role of ambidextrous IT and BPM capabilities at the business process level of analysis.

With the present work, we extend the findings of prior studies on different combination strategies for exploitation and exploration (Cao et al., 2009; Tang and Rai, 2014; Heckmann, 2015) by providing empirical evidence for this relationship. Furthermore, this research sheds light on the moderating role of BPM capabilities that has rarely been investigated in complementing BPIT capabilities (Zairi, 1997). All this means that companies that fail to develop these kinds of capabilities may risk not adapting their highly performant BP to changed market requirements, making these BP outdated and putting future profitability and sustainability at risk (Houy et al., 2010).

Prior research had identified the potential for BPM to affect firm performance through BPM capabilities (see Victor et al., 2013). Nevertheless, BPM can be ineffective in improving performance when the surrounding organization culture is not conducive (Green, 2012), in particular as related to IT capabilities. Therefore, this study contributes to the BPM research community by demonstrating the requirement to pursue adequate strategies for exploitative and explorative BPIT capabilities and to develop organizational BPM capabilities in order to amplify the effect of IT at the business process level (Heckmann, 2015).

Furthermore, to our knowledge there is even less research focusing on the IT ambidexterity phenomenon at the business process level (e.g. Xie et al., 2011). In fact, most of the studies focused more on the organizational level and on the mechanisms through which IT capability contributes to performance (e.g. Rai and Tang, 2010). This is particularly surprising as there are numerous calls for more micro-level research at the business process level in various research fields (Benner and Tushman, 2003; Melville et al., 2004). Still, existing studies on exploitative and explorative IT capabilities and BPP are conceptualized at the organizational level and thus are not suited for analyzing IT ambidexterity at the business process level. This is one of the most important contributions of this study.

From a practical point of view, this model can be useful as a guideline for process owners to be more aware of the level of investments in exploitative and explorative IT capabilities for a given business process in a specific business context. Practitioners can further benefit from our findings in the sense that contingency factors will be identified that can be used to determine adequate level of BPM capabilities depending upon specific business process characteristics and IT investments. Moreover, looking forward, we suggest that organizations should better address the role of what we call explorative BPM. In fact, when we see large corporate innovations across industries, it is usually not the process team that initiates or even leads those projects - we rarely see a BPM team proposing breakthrough innovations. As suggested by Michael Rosemann, "we do not think we have a sufficient academic or professional body of knowledge in the area of explorative BPM" (Kohlborn et al., 2014). In both practice and research, the notion of explorative BPM is a new frontier. Explorative BPM is quite different from exploitative BPM. It is opportunity-driven 
and follows an outside-in approach. From this approach, researchers may have the possibility to assess trends such as social media, big data, or the internet of Things in terms of their aptitude to innovate BP. Any large company has hundreds or thousands of processes. Instead of picking one of these processes and trying to improve it, the focus of explorative BPM is much more on assessing what new capabilities are emerging from modern technologies and asking which of the processes would benefit most from them.

\subsection{Limitations and future line of research}

While our paper has addressed the issue of explorative BPIT capabilities, more studies are needed on the mechanisms and the complementarities that firms need to develop to accomplish better results at the business process level. Further studies need to focus more on explorative change and not so much on exploitative execution. As exploration has been found to be more valuable in more dynamic industries (Tang and Rai, 2014), a further question is whether different combination strategies have the same impact depending on uncertainty features of this business process. Moreover, as suggested previously in this section, this study also addresses the call for more micro-level research on the topic of ambidexterity to understand the details of the inherent complexity to provide actable guidance for managers in practice.

Another limitation is related to our data that come from a single industry in a single country. In fact, data collection is limited to the hotel sector of Italy, putting our survey into a single cultural and geographical context. We are aware of these limitations but are still confident in our activities as we have guaranteed the validity and reliability of our developed constructs and scales based on prior studies. To validate and generalize our findings further, replication studies in other contexts could be seen as possible future research endeavors. Moreover, the emergence of business process ambidexterity over time remains an open question. In this case, the basis for developing business process theory could be provided by longitudinal approaches explaining how BPIT ambidexterity is developed over time in the form of diverse combination strategies for explorative and exploitative BPIT capabilities and how these strategies evolve over time.

Various study opportunities exist within this area, as suggested in the discussion. We aim at inspiring new research in the field on the combination strategies for exploitative and explorative BPIT capabilities. In fact, at the organizational level, several authors have already used balance and combined dimensions of ambidexterity in order to address the problem of trade-offs between the two diverse objectives (e.g. Cao et al., 2009). This is a limitation of our paper but, through these subsequent researches, we would like to stimulate new studies in this domain by increasing the understanding of BPIT ambidexterity and to contribute to practice as, for instance, process owners and IT managers who should be sensitized on the impact and possible interplays between exploitative and explorative BPIT and BPM capabilities in various environmental settings. For example, in cases of high environmental uncertainty, we believe that it is even more important to balance those dimensions to achieve sustained BPP. Future guidelines should be provided in order to help practitioners to find the delicate balance between overinvesting in explorative BPIT capabilities and being vulnerable to changing business conditions. 


\section{References}

Abernathy, W.J. (1978), The Productivity Dilemma, Johns Hopkins University, Baltimore, MD.

Adler, P.S. (1993), “Time-and-motion regained”, Harvard Business Review, Vol. 71 No. 1, pp. 97-108.

Aiken, L. and West, S. (1991), Multiple Regression: Testing and Interpreting Interactions, Sage, Newburg Park, CA.

Alter, S. (2014), “Theory of workarounds”, Communications of the Association for Information Systems, Vol. 34 No. 55, pp. 1041-1066.

Attaran, M. (2004), "Exploring the relationship between information technology and business process reengineering”, Information \& Management, Vol. 41 No. 5, pp. 585-596.

Bahli, B. and Ji, F. (2007), “An assessment of facilitators and inhibitors for the adoption of enterprise application integration technology: an empirical study”, Business Process Management Journal, Vol. 13 No. 1, pp. 108-120.

Benner, M.J. and Tushman, M.L. (2003), "Exploitation, exploration, and process management: the productivity dilemma revisited”, Academy of Management Review, Vol. 28 No. 2, pp. 238-256.

Bharadwaj, A.S. (2000), "A resource-based perspective on information technology capability and firm performance: an empirical investigation”, MIS Quarterly, Vol. 24 No. 1, pp. 169-196.

Bresciani, S., Ferraris, A. and Del Giudice, M. (2017), “The management of organizational ambidexterity through alliances in a new context of analysis: internet of things (IoT) smart city projects”, Technological Forecasting and Social Change, available at: https://doi.org/10.1016/j.techfore.20 17.03.002

Cao, Q., Gedajlovic, E. and Zhang, H. (2009), “Unpacking organizational ambidexterity: dimensions, contingencies, and synergistic effects”, Organization Science, Vol. 20 No. 4, pp. 781-796.

Carr, N. (2003), “IT doesn’t matter”, Harvard Business Review, May, pp. 41-49.

Cha, E.S., Kim, K.H. and Erlen, J.A. (2007), "Translation of scales in cross-cultural research: issues and techniques”, Journal of Advanced Nursing, Vol. 58 No. 4, pp. 386-395.

Chen, Y., Wang, Y., Nevo, S., Jin, J., Wang, L. and Chow, W.S. (2014), “IT capability and organizational performance: the roles of business process agility and environmental factors”, European Journal of Information Systems, Vol. 23 No. 3, pp. 326-342.

Chenhall, R. (2006), “Theorizing contingencies in management control systems research”, Handbook of Management Accounting Research, Vol. 1, pp. 163-205.

Ciabuschi, F., Dellestrand, H. and Martín, O.M. (2011), "Internal embeddedness, headquarters involvement, and innovation importance in multinational enterprises”, Journal of Management Studies, Vol. 48 No. 7, pp. 1612-1639.

Davenport, T.H. (1993), Process Innovation: Reengineering Work Through Information 
Technology, Harvard Business Press, Boston, MA.

Del Giudice, M. and Straub, D. (2011), "IT and entrepreneurism: an on-again, off-again love affair or a marriage?”, MIS Quarterly, Vol. 35 No. 4, pp. 3-11.

Dishaw, M.T. and Strong, D.M. (1999), "Extending the technology acceptance model with task-technology fit constructs”, Information \& Management, Vol. 36 No. 1, pp. 9-21.

Duncan, R.B. (1976), “The ambidextrous organization: designing dual structures for innovation”, The Management of Organization, Vol. 1, pp. 167-188.

Ferraris, A., Santoro, G. and Bresciani, S. (2017), "Open innovation in multinational companies' subsidiaries: the role of internal and external knowledge”, European Journal of International Management, Vol. 11 No. 4, pp. 452-468.

Ferraris, A., Santoro, G., Bresciani, S. and Carayannis, E.G. (2018), "HR practices for explorative and exploitative alliances in smart cities: evidences from smart city managers’ perspective”, Management Decision, Vol. 56 No. 6, pp. 1183-1197, available at: https://doi.org/10.1108/MD-0 4-2017-0384

Fornell, C. and Larcker, D.F. (1981), "Evaluating structural equation models with unobservable variables and measurement error”, Journal of Marketing Research, Vol. 18 No. 1, pp. 39-50.

Gebauer, J. and Schober, F. (2006), “Information system flexibility and the cost efficiency of business processes”, Journal of the Association for Information Systems, Vol. 7 No. 3, pp. 122-146.

Gibson, C.B. and Birkinshaw, J. (2004), “The antecedents, consequences, and mediating role of organizational ambidexterity”, Academy of Management Journal, Vol. 47 No. 2, pp. 209-226.

Goodhue, D.L. and Thompson, R.L. (1995), “Task-technology fit and individual performance”, MIS Quarterly, Vol. 19 No. 2, pp. 213-236.

Green, T.J. (2012), “TQM and organizational culture: how do they link? Total Quality”, Management \& Business Excellence, Vol. 23 No. 2, pp. 141-157.

Hackman, J.R. and Wageman, R. (1995), "Total quality management: empirical, conceptual, and practical issues”, Administrative Science Quarterly, Vol. 40 No. 2, pp. 309-342.

Hammer, M. and Stanton, S. (1999), “How process enterprises really work”, Harvard Business Review, Vol. 77, pp. 108-120.

Harman, H.H. (1967), Modern Factor Analysis, 3rd ed., University of Chicago Press, Chicago, IL. Hawes, J.M. and Crittenden, W.F. (1984), “A taxonomy of competitive retailing strategies”, Strategic Management Journal, Vol. 5 No. 3, pp. 275-287.

He, Z.-L. and Wong, P.-K. (2004), "Exploration vs. exploitation: an empirical test of the ambidexterity hypothesis”, Organization Science, Vol. 15 No. 4, pp. 481-494.

Heckmann, C. (2015), “The impact of business process IT ambidexterity on business process performance", Proceedings of the European Conference on Information Systems (ECIS), pp. 1-12, available at:

http://aisel.aisnet.org/cgi/viewcontent.cgi?article=1022\&context=ecis2015_rip

Hemmington, N. and King, C. (2000), "Key dimensions of outsourcing hotel food and beverage services”, International Journal of Contemporary Hospitality Management, Vol. 12 No. 4, pp. 256-261. 
Hoque, K. (1999), “New approaches to HRM in the UK hotel industry”, Human Resource Management Journal, Vol. 9 No. 2, pp. 64-76.

Houy, C., Fettke, P. and Loos, P. (2010), "Empirical research in business process management - analysis of an emerging field of research", Business Process Management Journal, Vol. 16 No. 4, pp. 619-661.

Hung, R.Y.Y. (2006), "Business process management as competitive advantage: a review and empirical study”, Total Quality Management \& Business Excellence, Vol. 17 No. 1, pp. 21-40.

Joachim, N., Beimborn, D. and Weitzel, T. (2013), "The influence of SOA governance mechanisms on IT flexibility and service reuse”, The Journal of Strategic Information Systems, Vol. 22 No. 1, pp. 86-101.

Kanuk, L. and Berenson, C. (1975), "Mail surveys and response rates: a literature review”, Journal of Marketing Research, Vol. 12 No. 4, pp. 440-453.

Karim, J., Somers, T.M. and Bhattacherjee, A. (2007), "The impact of ERP implementation on business process outcomes: a factor-based study”, Journal of Management Information Systems, Vol. 24 No. 1, pp. 101-134.

Kohlborn, T., Mueller, O., Poeppelbuss, J. and Roeglinger, M. (2014), “Interview with Michael Rosemann on ambidextrous business process management”, Business Process Management Journal, Vol. 20 No. 4, pp. 634-638.

Krstić, B., Jovanović, S. and Kahrović, E. (2012), "Process-oriented enterprise as a determinant of organization behavior in contemporary business term", Actual Problems of Economics, Vol. 11 No. 137, pp. 369-379.

Kumar, R.L. and Stylianou, A.C. (2014), “A process model for analyzing and managing flexibility in information systems”, European Journal of Information Systems, Vol. 23 No. 2, pp. 151-184.

Lee, O.-K.D., Lim, K.H., Sambamurthy, V. and Wei, K.K. (2008), “Information technology exploitation and exploration in a fast growing economy”, PACIS Proceedings, available at: http://aisel.aisnet. org/pacis2008/160

Ling, H., Zhao, F. and Wang, Y. (2009), "Impact of synergy between IT and business process on organizational performance: a perspective of ambidexterity theory", PACIS Proceedings, available at: http://aisel.aisnet.org/pacis2009/116

Looy, A.V., Backer, M.D. and Poels, G. (2011), "Defining business process maturity. a journey towards excellence”, Total Quality Management and Business Excellence, Vol. 22 No. 11, pp. 1119-1137.

Lu, Y. and Ramamurthy, K.R. (2011), "Understanding the link between information technology capability and organizational agility: an empirical examination”, MIS Quarterly, Vol. 35 No. 4, pp. 931-954.

March, J.G. (1991), "Exploration and exploitation in organizational learning”, Organization Science, Vol. 2 No. 1, pp. 71-87.

Melville, N., Kraemer, K. and Gurbaxani, V. (2004), "Review: information technology and organizational performance: an integrative model of IT business value”, MIS Quarterly, Vol.28 No.2, pp.283-322.

Muenstermann, B., Eckhardt, A. and Weitzel, T. (2010), "The performance impact of business process standardization”, Business Process Mgmt Journal, Vol. 16 No. 1, 
pp. 29-56.

Muenstermann, B., Joachim, N. and Beimborn, D. (2009), “An empirical evaluation of the impact of process standardization on process performance and flexibility”, AMCIS Proceedings.

Podsakoff, P.M. and Organ, D.W. (1986), "Self-reports in organizational research: problems and prospects”, Journal of Management, Vol. 12 No. 4, pp. 531-544.

Podsakoff, P.M., MacKenzie, S.B., Lee, J.Y. and Podsakoff, N.P. (2003), “Common method biases in behavioral research: a critical review of the literature and recommended remedies”, Journal of Applied Psychology, Vol. 88 No. 5, pp. 879903.

Rai, A. and Tang, X. (2010), "Leveraging IT capabilities and competitive process capabilities for the management of interorganizational relationship portfolios”, Information Systems Research, Vol. 21 No. 3, pp. 516-542.

Ravichandran, T. and Lertwongsatien, C. (2005), "Effect of information systems resources and capabilities on firm performance: a resource based perspective”, Journal of Management Information Systems, Vol. 21 No. 4, pp. 237-276.

Ray, G., Barney, J.B. and Muhanna, W.A. (2004), “Capabilities, business, processes, and com petitive advantage: choosing the dependent variable in empirical tests of the resource based view”, Strategic Management Journal, Vol. 25 No. 1, pp. 23-37.

Ray, G., Muhanna, W.A. and Barney, J.B. (2005), "Information technology and the performance of the customer service process: a resource-based analysis", MIS Quarterly, Vol. 25 No. 1, pp. 625-652.

Reinartz, W., Krafft, M. and Hoyer, W.D. (2004), "The customer relationship management process: its measurement and impact on performance”, Journal of Marketing Research, Vol. 41 No. 3, pp. 293-305.

Rosemann, M. and Brocke, J.V. (2010), “The six core elements of business process management”, Handbook on Business Process Management 1, Springer, Berlin and Heidelberg, pp. 107-122.

Salancik, G.R. and Pfeffer, J. (1977), "Who gets power - and how they hold on to it: a strategic- contingency model of power”, Organizational Dynamics, Vol. 5 No. 3, pp. 3-21.

Sambamurthy, V., Bharadwaj, A. and Grover, V. (2003), "Shaping agility through digital options: reconceptualizing the role of information technology in contemporary firms”, MIS Quarterly, Vol. 27 No. 2, pp. 237-263.

Schilling, M.A. (2000), “Toward a general modular systems theory and its application to interfirm product modularity”, Academy of Management Review, Vol. 25 No. 2, pp. 312-334.

Shang, S. and Seddon, P.B. (2002), "Assessing and managing the benefits of enterprise systems: the business manager's perspective”, Information Systems Journal, Vol. 12 No. 4, pp. 271-299.

Smith, H. and Fingar, P. (2003), IT doesn't Matter-Business Processes Do: A Critical Analysis of Nicholas Carr's IT Article in the Harvard Business Review, MeghanKiffer Press, Tampa, FL.

Strnadl, C.F. (2006), “Aligning business and it: the process-driven architecture model”, Information Systems Management, Vol. 23 No. 4, pp. 67-77. 
Tang, X. and Rai, A. (2014), "How should process capabilities be combined to leverage supplier relationships competitively?”, European Journal of Operational Research, Vol. 239 No. 1, pp. 119-129.

Thrassou, A., Vrontis, D. and Bresciani, S. (2014), "Strategic reflexivity in the hotel industry-a value- based analysis”, World Review of Entrepreneurship, Management and Sustainable Development, Vol. 10 Nos 1-2, pp. 352-371.

Tiwana, A., Konsynski, B. and Bush, A.A. (2010), "Research commentary-platform evolution: coevolution of platform architecture, governance, and environmental dynamics”, Information Systems Research, Vol. 21 No. 4, pp. 675-687.

Trkman, P. (2010), “The critical success factors of business process management”, International Journal of Information Management, Vol. 30 No. 2, pp. 125-134.

Victor, B.W., Mallory, F.M. and Nicole, M.G. (2013), “TQM and financial performance: are findings of direct effects methodological artefacts?”, Total Quality Management \& Business Excellence, Vol. 24 No. 2, pp. 171-187.

Vrontis, D., Thrassou, A., Santoro, G. and Papa, A. (2017), “Ambidexterity, external knowledge and performance in knowledge-intensive firms", The Journal of Technology Transfer, Vol. 42 No. 2, pp. 374-388.

Wade, M. and Hulland, J. (2004), "The resource-based view and information systems research: review, extension, and suggestions for future research”, MIS Quarterly, Vol. 28 No. 1, pp. 107-142.

Wong, W.P., Tseng, M.L. and Tan, K.H. (2014), “A business process management capabilities perspective on organisation performance”, Total Quality Management \& Business Excellence, Vol. 25 Nos 5-6, pp. 602-617.

Xie, R., Zhang, C. and Ling, H. (2011), "Effect of business process management on firm performance: an ambidexterity perspective”, International Conference on Business Management and Electronic Information (BMEI) (3), pp. 341-345.

Yamin, M. and Andersson, U. (2011), "Subsidiary importance in the MNC: what role does internal embeddedness play?”, International Business Review, Vol. 20 No. 2, pp. 151-162.

Zairi, M. (1997), "Business process management: a boundaryless approach to modern competitiveness”, Business Process Management Journal, Vol. 3 No. 1, pp. 64-80. 